\title{
SOCIAL MEDIA CAMPAIGNS CREATING AWARENESS REGARDING ORAL HEALTH DURING OUTBREAK OF COVID 19
}

\author{
Komal Ahmed \\ Assistant Professor/Publication and Communication Specialist ORIC \\ Kinnaird College for Women \\ Lahore - Pakistan \\ komal.ahmed@kinnaird.edu.pk \\ Maleeha Zamir \\ Fatima Memorial College of Medicine and Dentistry \\ Lahore - Pakistan
}

\begin{abstract}
With the exception of acute and emergency treatments, COVID-19 led in a reduction in dental office hours and, in certain cases, the closure of dental clinics, restricting routine treatment and preventative care (Zachary, B.D. and Weintraub, J.A., 2020). Treatments at the dentist's office can create aerosols, which can spread viruses. The pandemic provides an opportunity for dentists to shift away from surgical treatments and toward non-aerosol therapeutic alternatives that focus on prevention. The study focuses on social media activities and how they raise public awareness about oral health, much as it did during the Covid-19 pandemic. Therefore, it can be concluded on the basis of the findings that media campaigns can bring about awareness regarding oral health, and that youth is not inclined to oral health merely due to social media campaigns only, but social media campaigns did help the youth to become more aware.
\end{abstract}

Key Words : COVID-19,Social Media Campains, Awareness ,Oral Health

\section{Introduction:}

Ever since discovery in the Chinese city of Wuhan, the novel 2019 coronavirus (2019$\mathrm{nCoV}$ ) having propagated swiftly over the world. Millions of people have been infected and several have died as a result of this dangerous \& life-threatening illness. With

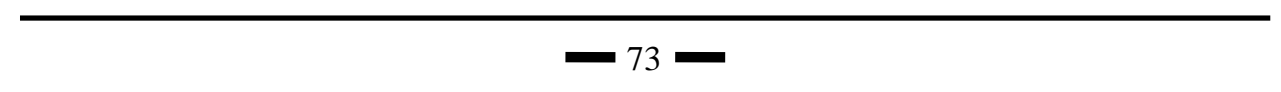




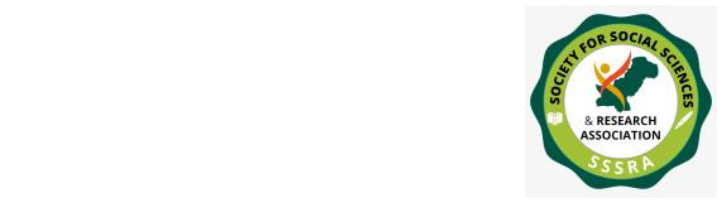

unexpected epidemics, the populace requires immediate \& accurate knowledge on illness signs as well as prevention. Currently, social media is frequently regarded as a rapid and convenient means of gathering, disseminating, \& distributing health info to the public. Furthermore, social media acts as an essential unofficial data set for identifying healthcare information which has not been disclosed to medical professionals or health agencies, as well as for discovering or sharing viewpoints on just about any lifethreatening wellbeing situations. However, this means of sharing information is often tainted by fear tactics, prejudice, fake claims, as well as unsubstantiated claims about the virus's origins, dissemination, \& widespread use of face masks, all of which have been strongly linked to current 21 st century "info media" social media channels. Despite the vital need of rapid access to knowledge in these circumstances, misconceptions or erroneous or false information for the purpose of rumours or untrustworthy news can cause confusion in the population, compounding the crisis. It can exacerbate the problem in low- and medium countries with insufficient health facilities, as these governments lack the necessary manpower as well as monetary resources to combat the pandemic (Sahni, H., \& Sharma, H., 2020). Several nations, on the other hand, appear to be coping at their own degree in their infancy, however the virus's probable course looks to be undetermined. As a result, this research gives a broad picture of the effects of social media on the general public mostly during CoV outbreak. Governments and public health experts must accept as well as manage the use of social media, collaborate, set limitations as well as rules for its usage, et, most importantly, enable it to serve the wider populace.

The COVID-19 epidemic having grave consequences for communal as well as private health, as well as social and emotional wellbeing, "and that" health care practitioners play a critical role in assessing behavioral needs and providing psychological assistance to their patients." There is a substantial link connecting oral health concerns including periodontal disease, erosion, as well as tooth decay with mood disorders including anxiety, stress, solitude, as well as depression, according to research. There are further possible links involving COVID-19 \& oral health in the future. With the effects of the COVID-19 virus on mental wellbeing, heightened risk concerns for oral health as a result of the outbreak, as well as expected declines in dental visits every capita, it would also be beneficial to promote integrative practice \& linkages among dentistry \& health practitioners. COVID-19 resulted in a reduction in dental practice hours and indeed the shutdown of dental practices, with the exception of immediate \& emergency treatments, restricting regular treatment \& preventive (Zachary, B.D. and Weintraub, J.A., 2020). Treatments at the dental office can produce aerosols, which can promote viral transmission. The pandemic presents a chance for the dentistry community to move away from surgical procedures but towards non-aerosol therapeutic options that emphasis on 


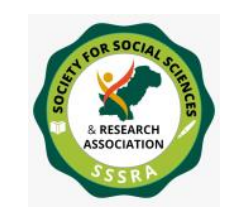

Pak. Journal of Int'L Affairs, Vol 4, Issue 3 (2021)

Social Media Campaigns Creating....

prevention. As during Covid-19 epidemic, the study focused on social media initiatives and how they improve public awareness about dental health.

\section{Literature Review:}

According to a study by Sahni, H., \& Sharma, H. (2020), a lot of possibly hazardous disinformation regarding the COVID-19 epidemic has been created, and a lot of it has being circulated throughout social media. This false information includes several aspects of the pandemic that might endanger public health and safety, further complicating crisis response. This bogus COVID-19 myth is growing bigger than the illness itself, and it feels that HCPs are combating both the virus and indeed the related disinformation at the same time. The methodology used in the article was secondary research based on qualitative analysis. The study's strength is that it examines \& discusses the good as well as negative effects of social media on healthcare professionals and people amid the coronavirus outbreak. The flaw is that it implies that the major technique proposed in this research was also to rectify professionals' misunderstandings in healthcare facilities. Although some studies suggest that proper information may not be beneficial in a public health emergency, others have found that delivering $\&$ disseminating genuine data from health professionals is useful.

Another study by Liu, C. W. N., \& Onudiwe, F. (2020), COVID-19 is raising the level of unexpected events. It has been challenging for everyone to talk about health promotion strategies with various groups \& municipal governments. Whenever dental access is restricted, it is critical to provide preventative information. Ones participation in social health \& social media initiatives would make a significant difference in the oral health and general well-being of the society as we surmount technological as well as communication challenges. The methodology of the study is was personal outreach by authors (healthcare professionals), a primary research based on qualitative evidences. The study's strength is that the authors employed a variety of methods to connect out to various age groups within the community. They communicated with children and adolescents in anticipation through visiting to local schools \& involvement in community events in order to lead them towards that healthy oral lifestyle. The flaw is that it was not based on enough numbers and data from the people polled.

As per a study by Rajeh, M. (2020), During the coronavirus outbreak, highly qualified Saudi individuals displayed strong understanding as well as better emotions regarding maintaining safe procedures in the dental setting in order to prevent the spread of COVID-19. This shows that large-scale health awareness initiatives led by local governments and thus the Ministry of Health were beneficial. Employing SurveyMonkey, 


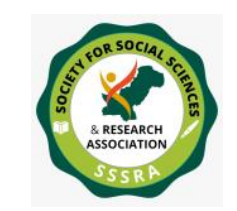

an online questionnaire was produced and distributed to the public at randomness via social media sites. Due to existing government constraints, the author largely advertised the poll via WhatsApp, Facebook, \& Twitter messaging, with receivers being encouraged to spread it with their connections. The study is qualitative based on secondary data. The study's strength is that it shine some light on an area wherein research is scarce, and this is the first study to measure public knowledge of COVID-19 throughout a visit to a dental clinic in Saudi Arabia, as far as we understand. The findings imply that the municipal government as well as the Ministry of Health's continuous extensive health education campaigns have been successful in persuading the population to implement proper COVID-19 prevention measures. The data was self-reported by the respondents using an online survey, which was one of the flaws. Self-reported material cannot be independently checked and thus is prone to response bias, including people overstating or underestimating their replies. Furthermore, poorly designed social media methods might result in skewed data $\&$ restrict the generalisation of conclusions.

As per a study by Zachary, B. D., \& Weintraub, J. A. (2020), Oral illness is more common among populations significantly impacted by coronavirus 2019 illness (COVID$19)$, and inequities in oral health as well as oral health treatment are more common. Exception of emergency \& urgent treatments, COVID-19 has resulted in the closure \& restriction of dental practice times, restricting regular treatment \& protection. The study's strength is that it reveals that COVID-19 and oral health may have additional possible downward linkages. This will be beneficial to promote coordinated practice \& referral amongst dental \& psychiatric health professionals, given the impact of the COVID-19 outbreak on mental wellbeing, pandemic-related rises in oral health conditions, as well as expected reduction in dental visits per population. The study's main flaw is its narrow area of investigation.

\section{Methodology:}

The research was conducted in a qualitative manner. Qualitative research design, as per Merriam, S. B., and Grenier, R. S. (Eds.). (2019), is superior at acquiring knowledge regarding attitudes, beliefs, as well as intentions. This sort of design, according to a study, allows the researcher to gather data on numerous elements in a systematic manner while without limiting the respondents' ability to supply the information needed for the study. The study will utilize questionnaire method for analysis of findings. The study will utilize SPSS for chi square testing for hypothesis and analysis of questionnaire.

\section{Research Questions:}


Q1: Do you think media campaigns can bring about awareness regarding oral health? Q2: Is youth more inclined to oral health due to social media campaigns? Q3: Do you think social media campaigns helped youth to become more aware?

\section{Discussion \& Analysis:}

\section{Q1. Are you aware of the concept of good oral health?}

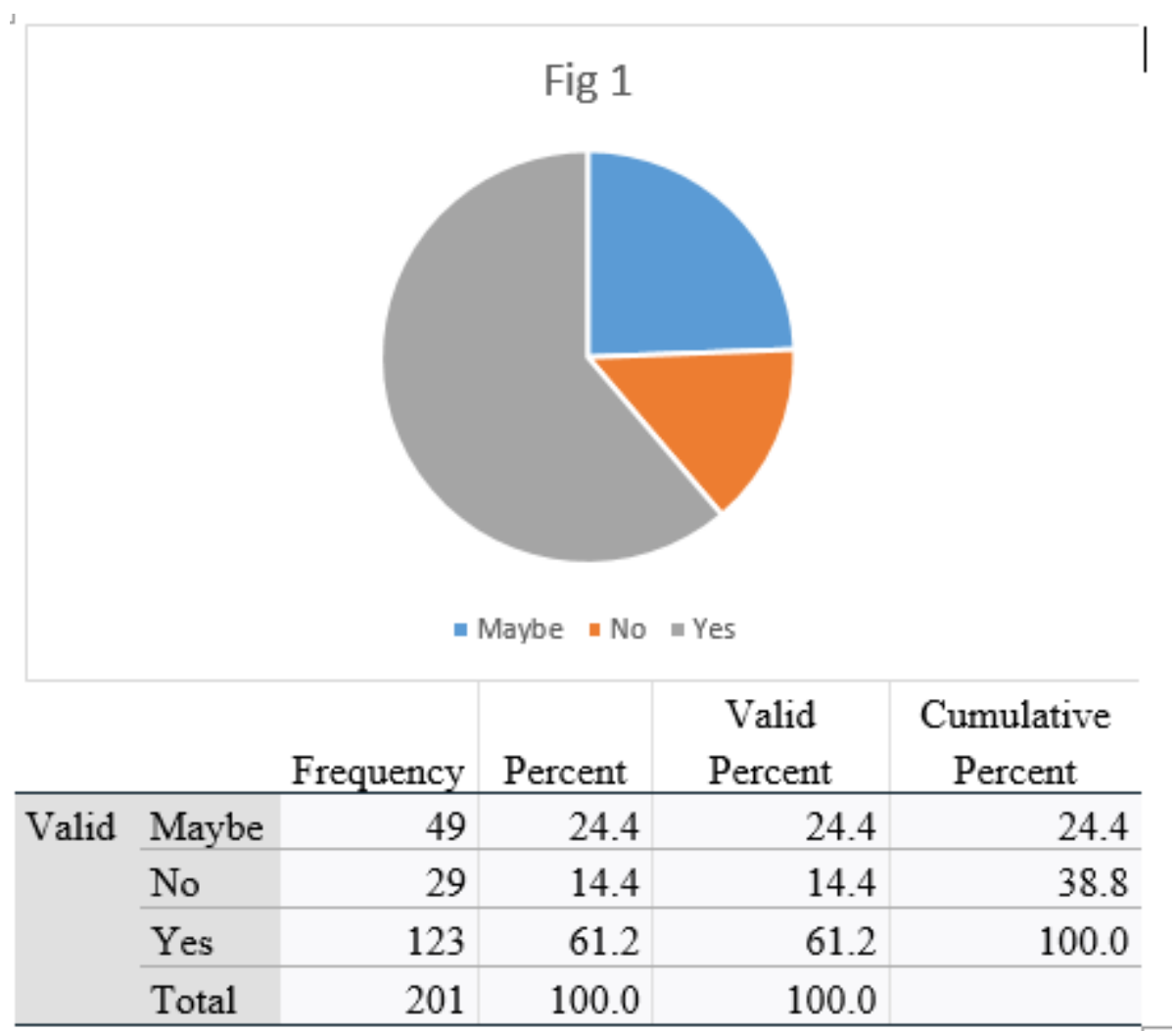

of the total respondents, $61.2 \%$ said that they are aware of the concept of good oral health, $14.4 \%$ said no, and $24.4 \%$ said may be. 
Q2. Have you felt any change in your oral health after prolonged mask usage?

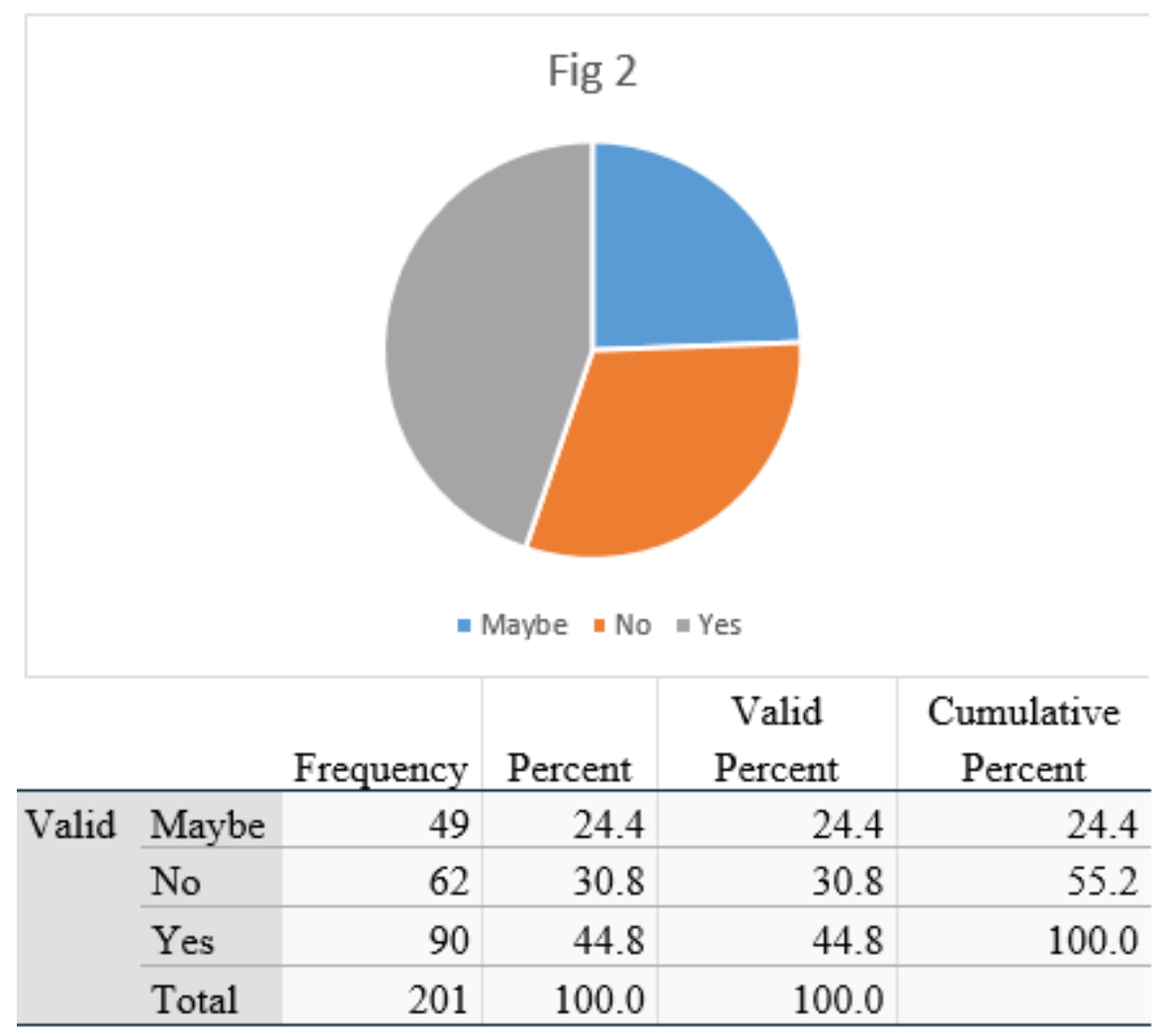

Of the total respondents, $44.8 \%$ said that they did feel change in their oral health after prolonged mask usage, $30.8 \%$ said no, and $24.4 \%$ said may be 
Q3. Do you experience bad breath by wearing mask for a long period?

\begin{tabular}{|c|c|c|c|c|c|}
\hline \multicolumn{6}{|c|}{ Fig 3} \\
\hline \multicolumn{6}{|c|}{ - Maybe " No - Yes } \\
\hline & & Frequency & Percent & $\begin{array}{c}\text { Valid } \\
\text { Percent }\end{array}$ & $\begin{array}{c}\text { Cumulative } \\
\text { Percent }\end{array}$ \\
\hline \multirow[t]{4}{*}{ Valid } & Maybe & 64 & 31.8 & 31.8 & 31.8 \\
\hline & No & 55 & 27.4 & 27.4 & 59.2 \\
\hline & Yes & 82 & 40.8 & 40.8 & 100.0 \\
\hline & Total & 201 & 100.0 & 100.0 & \\
\hline
\end{tabular}

Of the total respondents, $40.8 \%$ said that they experienced bad breath after wearing a mask for a long period, $27.4 \%$ said no, and $31.8 \%$ said may be. 
Q4. Are you more concerned about your oral health during COVID-19?

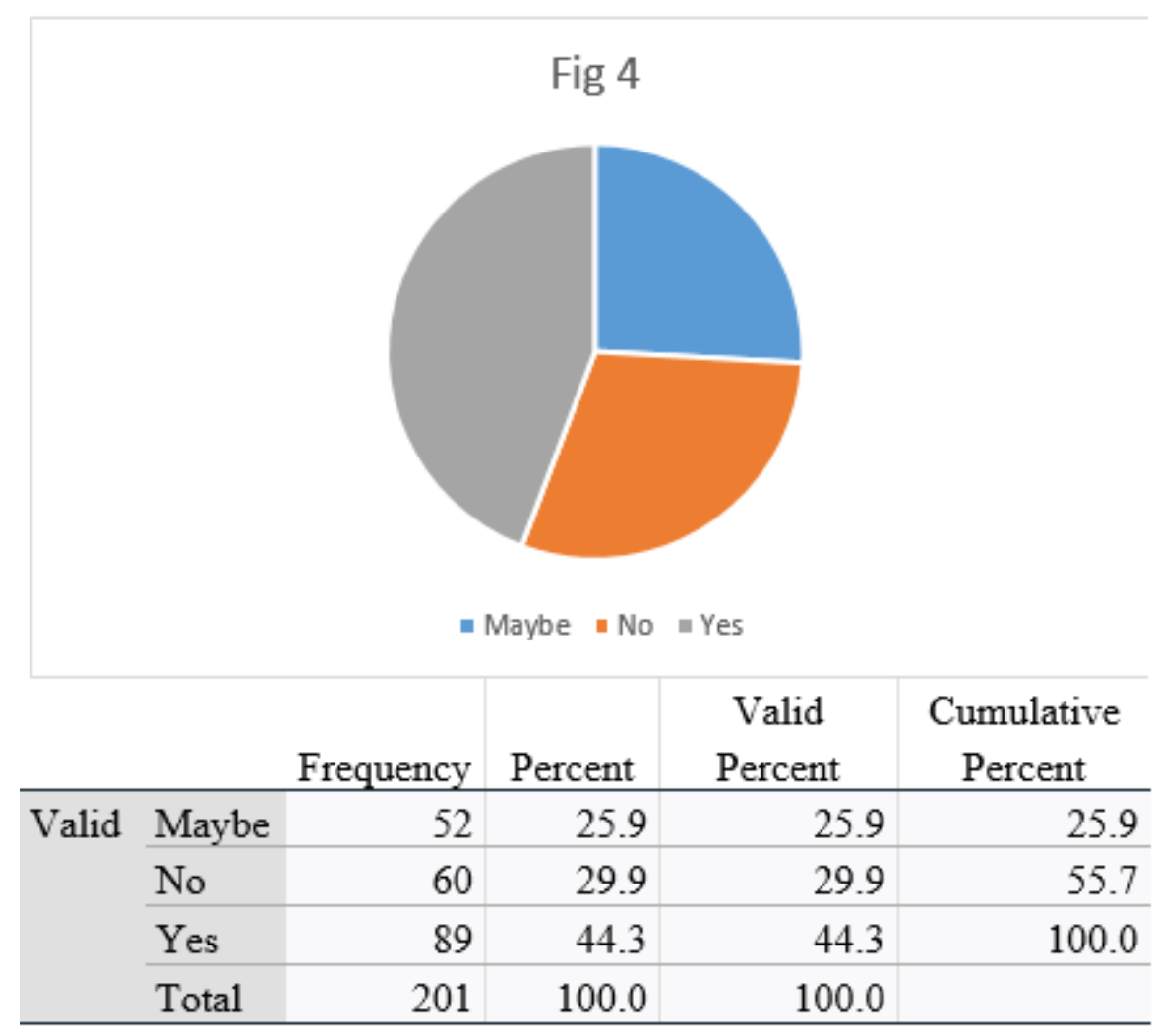

Of the total respondents, $44.3 \%$ said that they are more concerned about oral health during Covid-19, 29.9\% said no, and $25.9 \%$ said may be. 
Q5. Did you experience more dental problems during the pandemic?

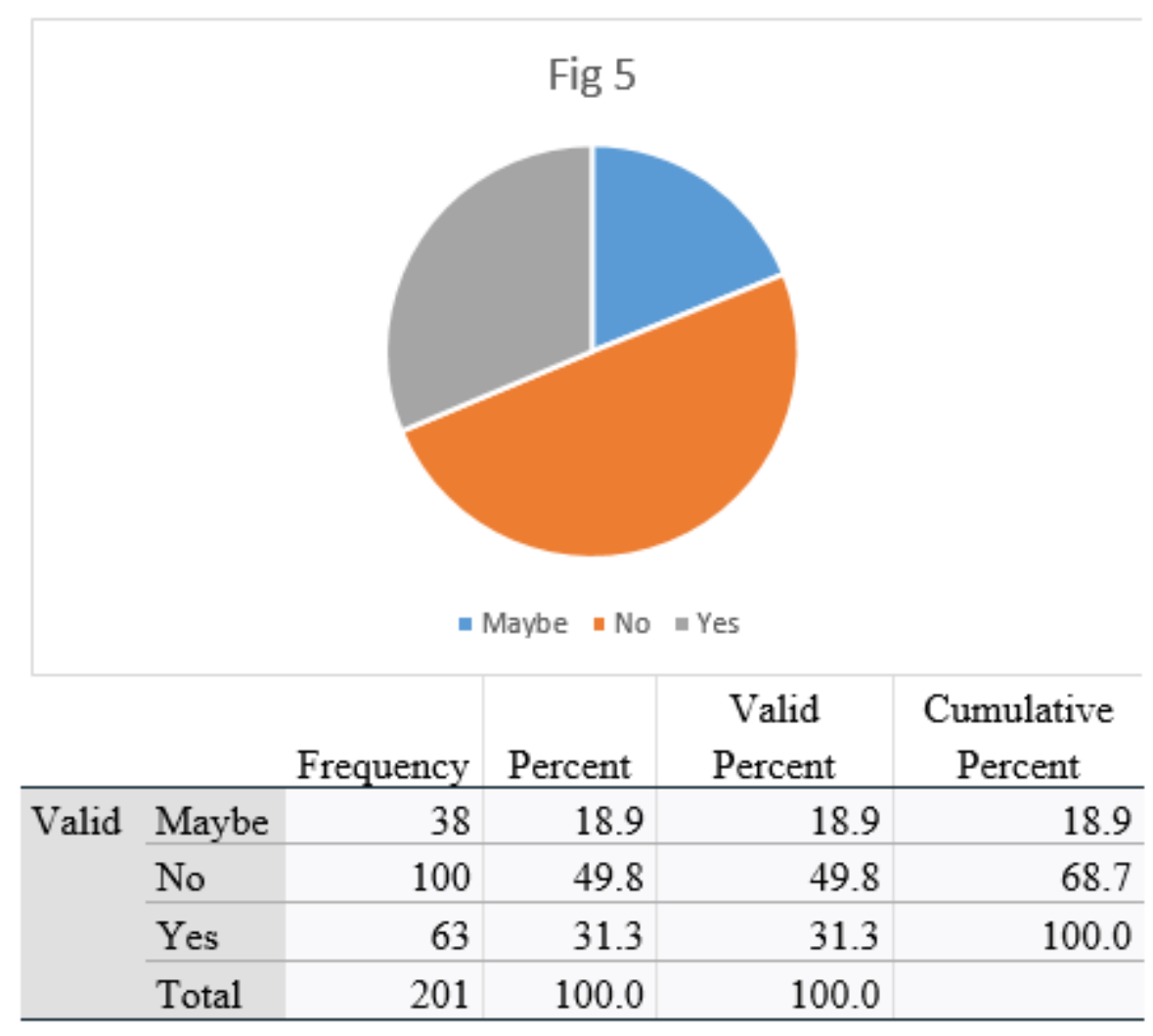

Of the total respondents, $31.3 \%$ said that they experienced more dental problems during the pandemic, $49.8 \%$ said no, and $18.9 \%$ said may be. 
Q6. Do you think media campaigns can bring about awareness regarding oral health?

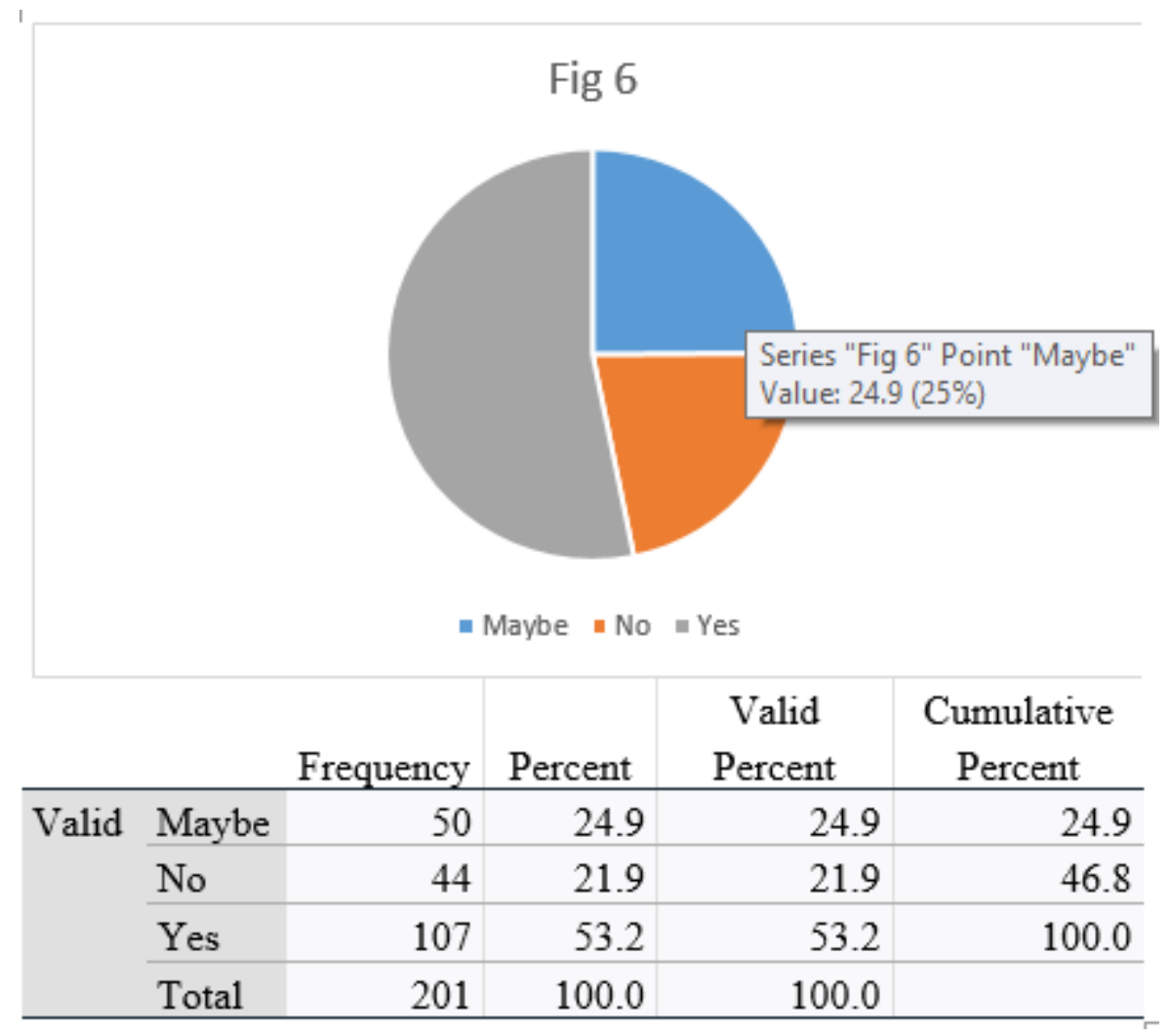

Of the total respondents, $53.2 \%$ said media campaigns can bring about awareness regarding oral health, $21.9 \%$ said no, and $24.9 \%$ said may be. 
Q7. Have you come across any media campaigns during pandemic regarding oral health?

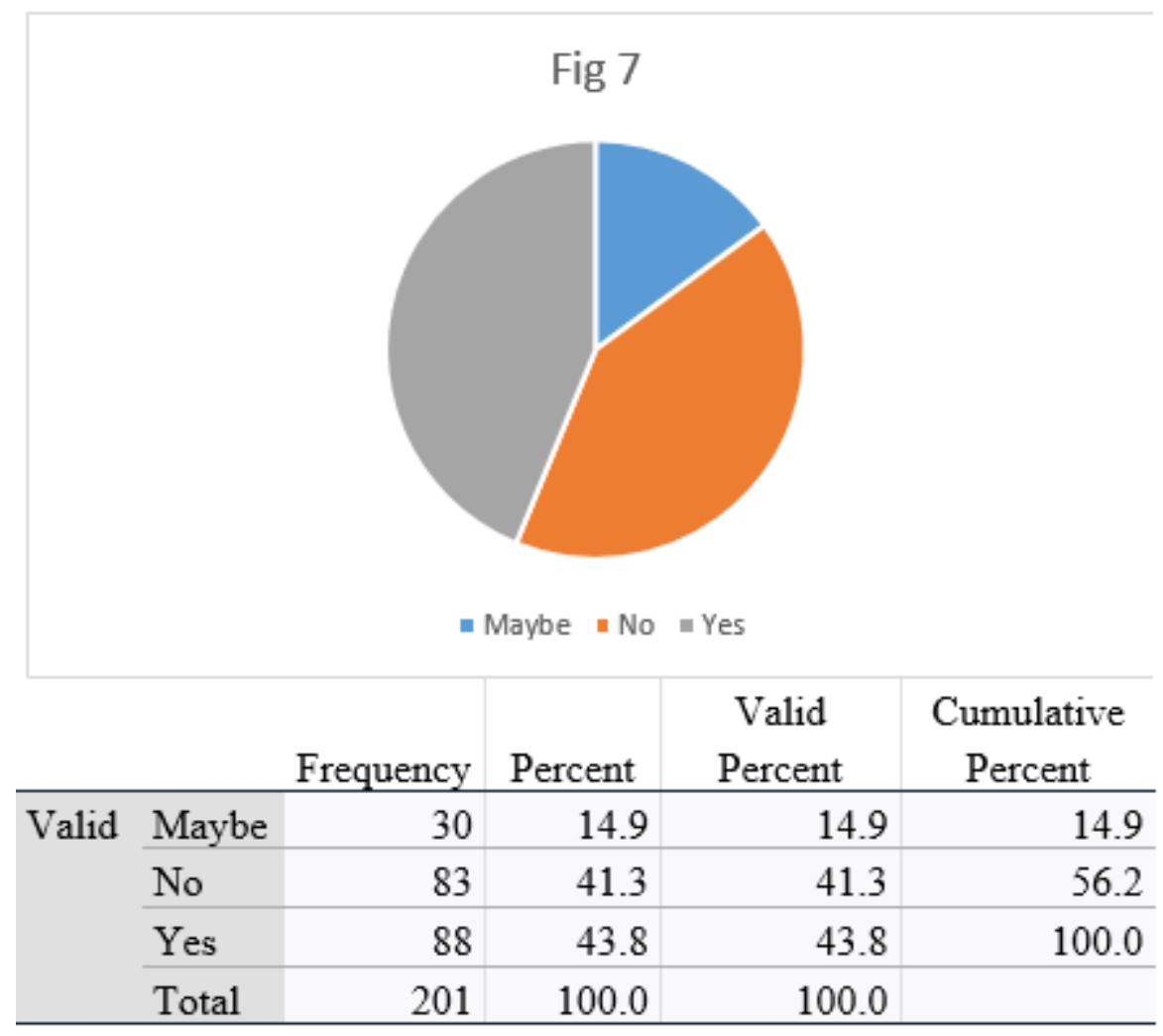

Of the total respondents, $43.8 \%$ said that they have come across media campaign regarding oral health during the pandemic, $41.3 \%$ said no, and $14.9 \%$ said may be. 
Q8. Is youth more inclined to oral health due to social media campaigns?

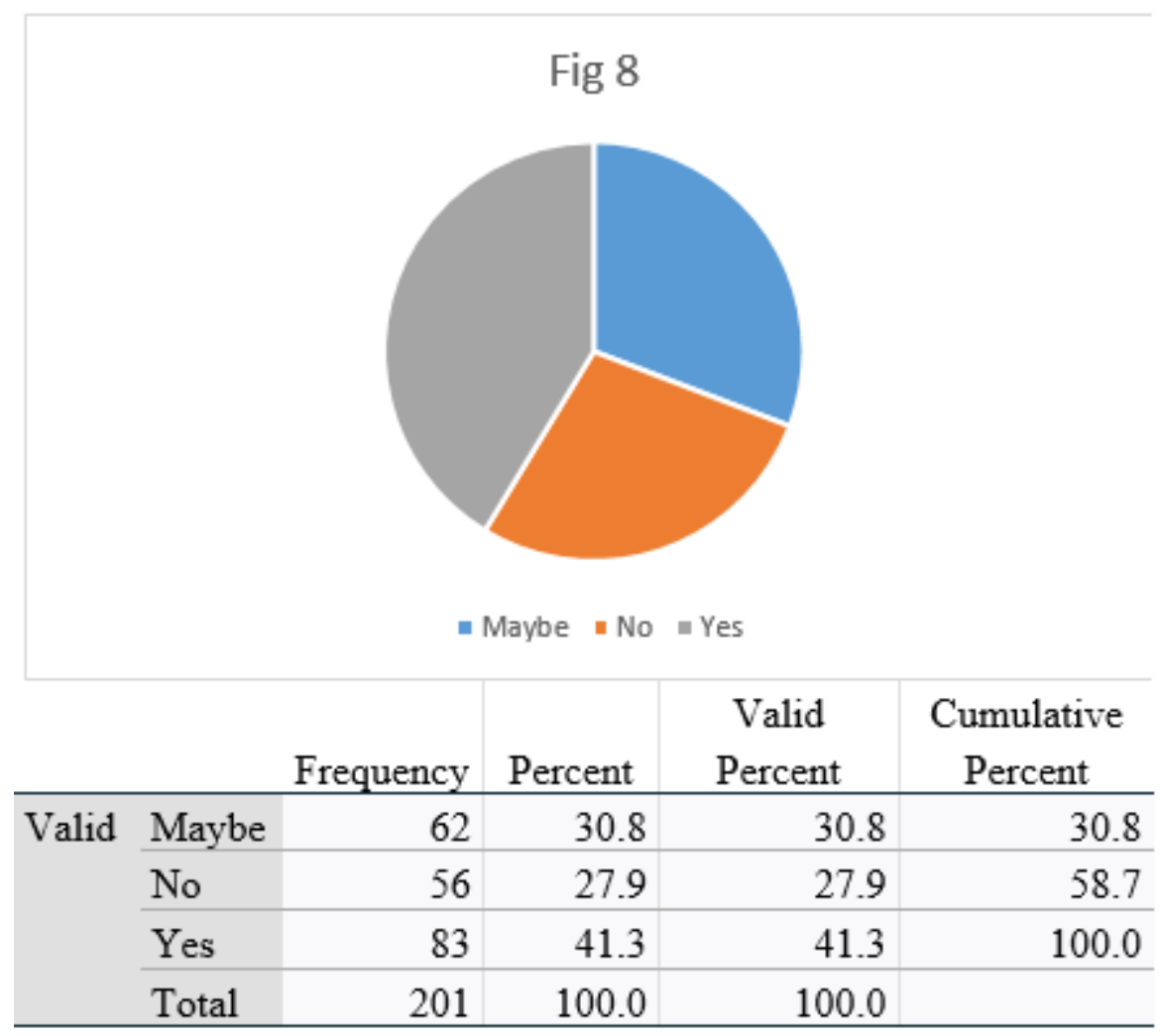

Of the total respondents, $41.3 \%$ said that youth are more inclined to oral health due to social media campaigns, $27.9 \%$ said no, and $30.8 \%$ said may be. 
Q9. Have you added additional oral health maintenance products during Covid-19?

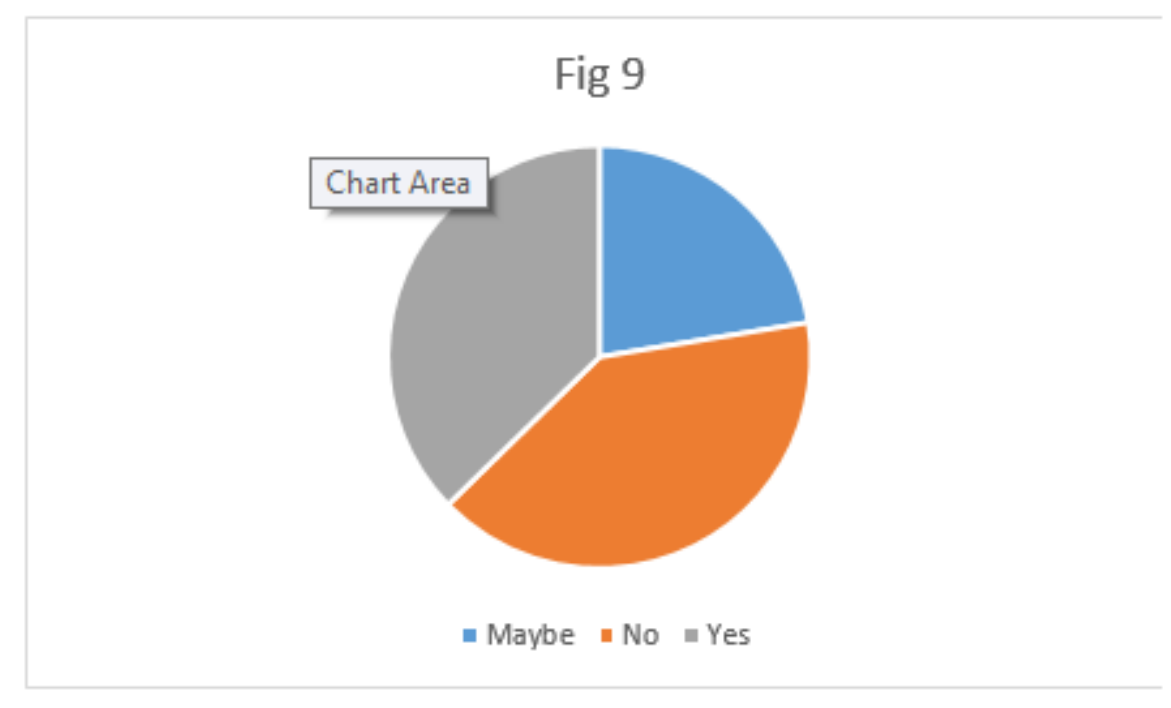

\begin{tabular}{rl|r|r|r|r} 
& & & \multicolumn{2}{c}{$\begin{array}{c}\text { Valid } \\
\text { Percent }\end{array}$} & $\begin{array}{c}\text { Cumulative } \\
\text { Percent }\end{array}$ \\
\hline Valid & Maybe & 45 & 22.4 & 22.4 & 22.4 \\
\cline { 2 - 6 } & No & 81 & 40.3 & 40.3 & 62.7 \\
\cline { 2 - 6 } & Yes & 75 & 37.3 & 37.3 & 100.0 \\
\hline & Total & 201 & 100.0 & 100.0 & \\
\hline
\end{tabular}

Of the total respondents, $37.3 \%$ said that they added additional oral health maintenance products during Covid-19, $40.3 \%$ said no, and $22.4 \%$ said may be. 
Q10. Have your brushing habits changed after watching media campaigns?

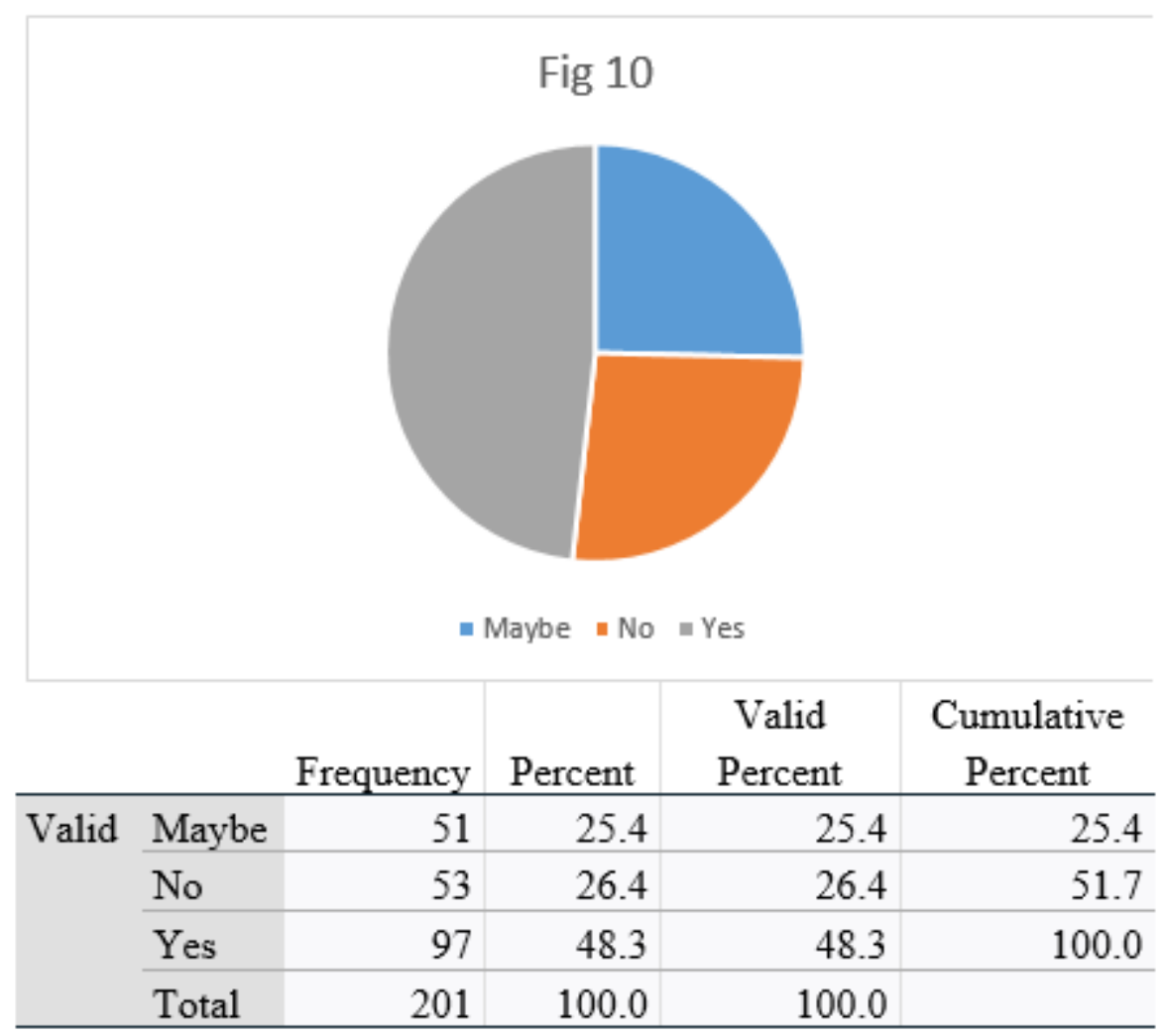

Of the total respondents, $48.3 \%$ said that their brushing habits changed after watching media campaigns, $26.4 \%$ said no, and $25.4 \%$ said may be. 
Q11. Do you think media campaign persuaded you to take extra care?

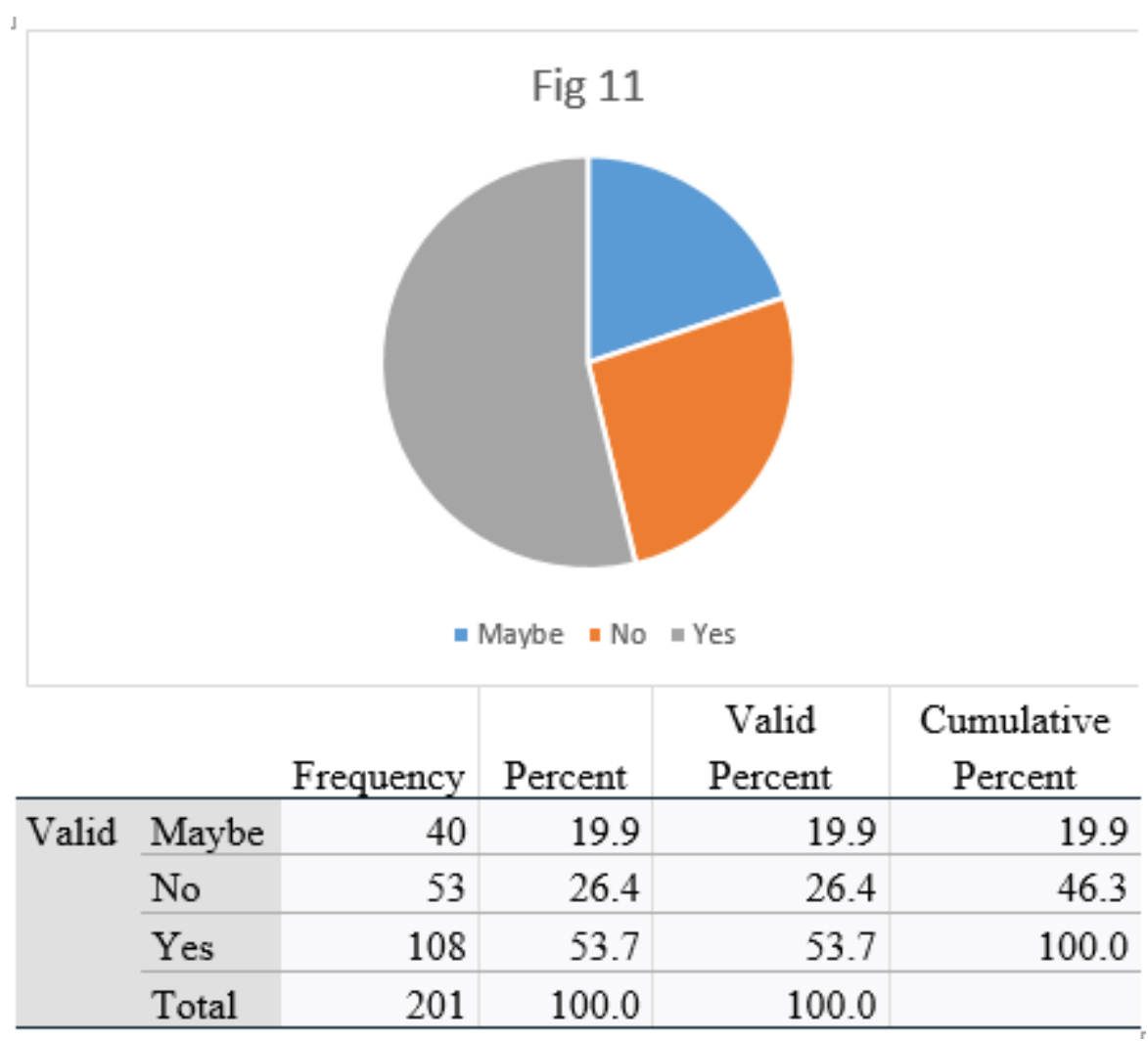

Of the total respondents, $53.7 \%$ said that media campaign persuaded them to take extra care, $26.4 \%$ said no, and $19.9 \%$ said may be. 
Q12. Do you think social media campaigns helped youth to become more aware?

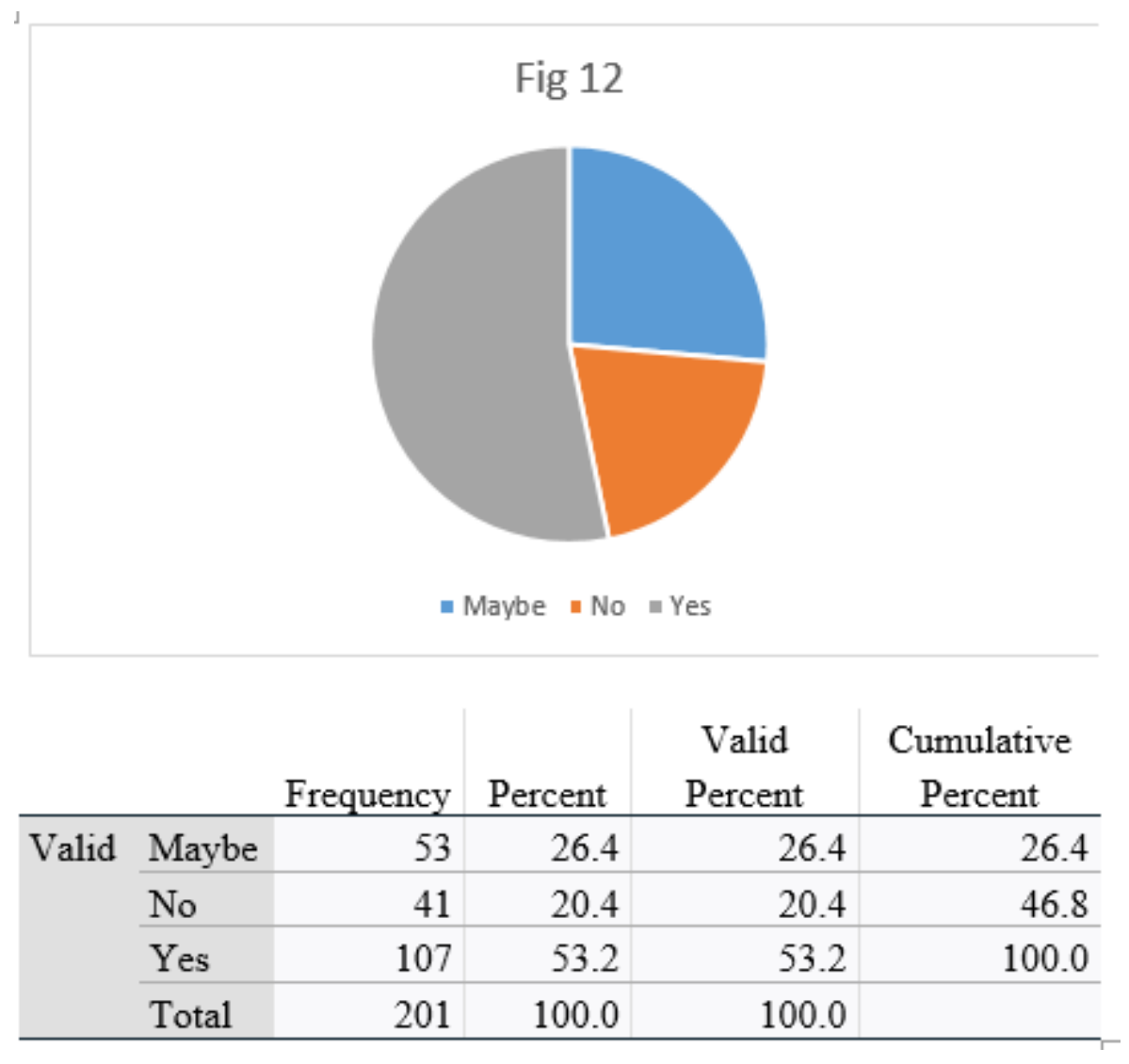

Of the total respondents, $53.2 \%$ said that they think social media campaigns helped youth to become more aware, $20.4 \%$ said no, and $26.4 \%$ said may be. 


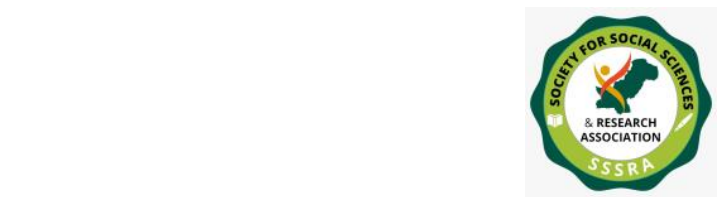

\section{Findings:}

61.2 percent of all respondents indicated they are aware of the notion of excellent dental health, 14.4\% answered no, and 24.4 percent said they may be. 44.8 percent of all respondents stated they saw a difference in their dental health after using a mask for a long time, 30.8 percent answered no, and 24.4 percent thought it was possible. 40.8 percent of all respondents stated they had foul breath after wearing a mask for a long time, 27.4 percent answered no, and 31.8 percent said it was possible. 44.3 percent of all respondents stated they are more concerned about dental health during Covid-19, 29.9\% answered no, and $25.9 \%$ said may be. 31.3 percent of respondents claimed they had greater dental issues during the pandemic, 49.8 percent answered no, and 18.9 percent thought it was possible. 53.2 percent of the total respondents believed media efforts can raise oral health awareness, 21.9 percent answered no, and 24.9 percent said maybe.

43.8 percent of the total respondents stated they had seen a media campaign on oral health during the pandemic, 41.3 percent answered no, and 14.9 percent thought it was possible. 41.3 percent of the total respondents indicated that social media ads had made youth more interested in oral health, $27.9 \%$ answered no, and 30.8 percent thought it may be. 37.3 percent of respondents stated they added more oral health maintenance goods during Covid-19, 40.3 percent answered no, and 22.4 percent thought it was possible. When asked if their brushing habits had altered as a result of viewing media ads, 48.3 percent responded yes, 26.4 percent said no, and 25.4 percent indicated it was possible. 53.7 percent of respondents stated a media campaign convinced them to take extra precautions, 26.4 percent answered no, and 19.9 percent thought may be. 53.2 percent of respondents thought social media marketing helped youth become more conscious, 20.4 percent answered no, and 26.4 percent said it may have helped.

\section{Hypothesis 1:}

$\mathrm{H}_{\mathrm{o}}=$ Media campaigns cannot bring about awareness regarding oral health

$\mathrm{H}_{1}=$ Media campaigns can bring about awareness regarding oral health 


\begin{tabular}{rlr|r|r|r} 
& & & \multicolumn{2}{c}{$\begin{array}{c}\text { Valid } \\
\text { Percent }\end{array}$} & $\begin{array}{c}\text { Cumulative } \\
\text { Percent }\end{array}$ \\
\hline Valid & Maybe & 50 & 24.9 & 24.9 & 24.9 \\
\cline { 2 - 6 } & No & 44 & 21.9 & 21.9 & 46.8 \\
\hline & Yes & 107 & 53.2 & 53.2 & 100.0 \\
\hline Total & 201 & 100.0 & 100.0 & \\
\hline
\end{tabular}

\begin{tabular}{|c|c|c|c|}
\hline \multicolumn{4}{|c|}{ Chi-Square Tests } \\
\hline & Value & $\mathrm{df}$ & $\begin{array}{c}\text { Asymptotic } \\
\text { Significance } \\
\text { (2-sided) }\end{array}$ \\
\hline $\begin{array}{l}\text { Pearson Chi- } \\
\text { Square }\end{array}$ & $3.190^{\mathrm{a}}$ & 2 & .203 \\
\hline Likelihood Ratio & 3.162 & 2 & .206 \\
\hline $\mathrm{N}$ of Valid Cases & 201 & & \\
\hline
\end{tabular}

a. 0 cells $(0.0 \%)$ have expected count less than 5 . The minimum expected count is 18.83 .

$\mathrm{p}=0.532$

$\mathrm{P}-$ value $=0.203$

Hence, hypothesis $\mathrm{H}_{1}$ stands true.

\section{Hypothesis 2:}

$\mathrm{H}_{\mathrm{o}}=$ Youth is not inclined to oral health due to social media campaigns $\mathrm{H}_{1}=$ Youth is more inclined to oral health due to social media campaigns 


\begin{tabular}{rlr|r|r|r} 
& & & \multicolumn{2}{c}{$\begin{array}{c}\text { Valid } \\
\text { Percent }\end{array}$} & $\begin{array}{c}\text { Cumulative } \\
\text { Percent }\end{array}$ \\
\hline Valid & Maybe & 62 & 30.8 & 30.8 & 30.8 \\
\cline { 2 - 7 } & No & 56 & 27.9 & 27.9 & 58.7 \\
\hline & Yes & 83 & 41.3 & 41.3 & 100.0 \\
\hline Total & 201 & 100.0 & 100.0 & \\
\hline
\end{tabular}

\begin{tabular}{|c|c|c|c|}
\hline \multicolumn{4}{|c|}{ Chi-Square Tests } \\
\hline & Value & $\mathrm{df}$ & $\begin{array}{c}\text { Asymptotic } \\
\text { Significance } \\
\text { (2-sided) }\end{array}$ \\
\hline $\begin{array}{l}\text { Pearson Chi- } \\
\text { Square }\end{array}$ & $1.296^{\mathrm{a}}$ & 2 & .523 \\
\hline Likelihood Ratio & 1.296 & 2 & .523 \\
\hline $\mathrm{N}$ of Valid Cases & 201 & & \\
\hline
\end{tabular}

a. 0 cells $(0.0 \%)$ have expected count less than 5 . The minimum expected count is 23.96 .

$\mathrm{p}=0.413$

$\mathrm{P}-$ value $=0.523$

Hence, hypothesis $\mathrm{H}_{1}$ is rejected.

\section{Hypothesis 3:}

$\mathrm{H}_{\mathrm{o}}=$ Social media campaigns did not help youth to become more aware $\mathrm{H}_{1}=$ Social media campaigns helped youth to become more aware 


\begin{tabular}{rlr|r|r|r} 
& & & \multicolumn{2}{c}{$\begin{array}{c}\text { Valid } \\
\text { Percent }\end{array}$} & $\begin{array}{c}\text { Cumulative } \\
\text { Percent }\end{array}$ \\
\hline Valid & Maybe & 53 & 26.4 & 26.4 & 26.4 \\
\cline { 2 - 6 } & No & 41 & 20.4 & 20.4 & 46.8 \\
\cline { 2 - 6 } & Yes & 107 & 53.2 & 53.2 & 100.0 \\
\hline Total & 201 & 100.0 & 100.0 & \\
\hline
\end{tabular}

\section{Chi-Square Tests}

\begin{tabular}{|c|c|c|c|}
\hline & Value & $\mathrm{df}$ & $\begin{array}{c}\text { Asymptotic } \\
\text { Significance } \\
\text { (2-sided) }\end{array}$ \\
\hline $\begin{array}{l}\text { Pearson Chi- } \\
\text { Square }\end{array}$ & $9.359^{\mathrm{a}}$ & 2 & .009 \\
\hline Likelihood Ratio & 9.322 & 2 & .009 \\
\hline $\mathrm{N}$ of Valid Cases & 201 & & \\
\hline
\end{tabular}

a. 0 cells $(0.0 \%)$ have expected count less than 5 . The minimum expected count is 17.54 .

$\mathrm{p}=0.532$

P- value $=0.009$

Hence, hypothesis $\mathrm{H}_{1}$ holds true (significantly).

\section{Conclusion:}

The COVID-19 epidemic is wreaking havoc on public and private health, as well as social and emotional well-being, "and" health care providers play a vital role in assessing behavioral needs and providing psychological support to their patients. According to studies, there is a significant relationship between oral health issues including periodontal disease, erosion, and tooth decay and mood problems like anxiety, stress, isolation, and depression. In the future, there may be further connections between COVID-19 and 
dental health. With the impact of the COVID-19 virus on mental health, increased risk implications for oral health as a result of the epidemic, and projected decreases in dental visits per capita, promoting integrative practice and connections across dentistry and health practitioners might be helpful. With the exception of acute and emergency treatments, COVID-19 led in a reduction in dental office hours and, in certain cases, the closure of dental clinics, restricting routine treatment and preventative care (Zachary, B.D. and Weintraub, J.A., 2020). 37.3 percent of respondents stated they added more oral health maintenance goods during Covid-19, 40.3 percent answered no, and 22.4 percent thought it was possible. When asked if their brushing habits had altered as a result of viewing media ads, 48.3 percent responded yes, 26.4 percent said no, and 25.4 percent indicated it was possible. 53.7 percent of respondents stated a media campaign convinced them to take extra precautions, 26.4 percent answered no, and 19.9 percent thought it may. Therefore, it can be concluded on the basis of the findings that media campaigns can bring about awareness regarding oral health, and that youth is not inclined to oral health merely due to social media campaigns only, but social media campaigns did help the youth to become more aware. 


\section{References:}

Liu, C. W. N., \& Onudiwe, F. (2020). The'new normal'in oral health promotion.

Merriam, S. B., \& Grenier, R. S. (Eds.). (2019). Qualitative research in practice: Examples for discussion and analysis. John Wiley \& Sons.

Rajeh, M. (2020). COVID-19 and Infection Control in Dental Clinics; Assessment of Public Knowledge, Attitudes and Practices in Several Regions of Saudi Arabia. The Open Dentistry Journal, 14(1).

Sahni, H., \& Sharma, H. (2020). Role of social media during the COVID19 pandemic: Beneficial, destructive, or reconstructive?. International Journal of Academic Medicine, 6(2), 70.

Zachary, B. D., \& Weintraub, J. A. (2020). Oral Health and COVID-19: Increasing the Need for Prevention and Access. Preventing Chronic Disease, 17. 